\title{
HET MERKWAARDIGE EILAND-KARAIBISCH
}

DOOR

\section{H. DE GOEJE}

Die merkwaardige dingen, die bij een ver doorgezette ontleding uit het Arawaksch, het Warau en het Karaïbisch van Surinam, te voorschijn kwamen ${ }^{1}$ ), kan men ook vinden in de taal van de bewoners der Kleine Antillen, de Eiland-Karaïben, en hun afstammelingen in Britsch Honduras. Maar hier wil ik alleen spreken over een merkwaardigheid van geheel anderen aard: de tweetaligheid van dit volk, vrouwentaal en mannentaal.

De oudste geschreven berichten over Karaïben, staan in het verhaal van de eerste reis van Columbus. Op de Bahama's en Groote Antillen kwam men in aanraking met inboorlingen, die ik overeenkomstig het gebruik Taino's zal noemen. En die Taino's vertelden van een ander volk, dat uit het Zuiden opdrong; gevaarlijke vijanden, menscheneters, er werd zelfs gezegd: menschen met snuiten als honden en met slechts één oog.

Wij weten thans, dat dit Indianen waren van het nu nog in Guyana wonende volk dat zichzelve Kaliñ $a$ of Karín $a$ noemt, en/of hun op de Kleine Antillen gevestigde afstammelingen. Die naam is zeer waarschijnlijk ontstaan uit een ouden naam *Karipona, die ook de andere volken der z.g. karibische taalfamilie omvatte. Ongeveer dien naam zullen de Taino's gebezigd hebben, toen zij hun vijanden aanduidden. De Spanjaarden hebben vermoedelijk niet goed verstaan, en zoo zijn er verschillende variaties opgeschreven geworden, waarvan er drie gebleven zijn: $1^{\circ}$ Caribana, naam van het benedenland van Guyana, thans in onbruik; $2^{\circ}$ Canibal(e), aanvankelijk naam voor eiland- en vastelands-Karaïben, later woord met de algemeene beteekenis van „menscheneter" $\left.{ }^{2}\right) ; 3^{\circ}$ Carib(e), naam van de eiland- en vastelands-Karaïben.

1) Zie de West-Ind. Gids XI, XII, XIV.

2) Ik houd het ervoor, dat Shakespeare, die meer aan Amerika heeft ontleend, hieraan gedacht heeft bij het scheppen van de figuur van Caliban in The Tempest.

West-Indische Gids XVII 
De naam Caraìbe is, voor zoover ik heb kunnen nagaan, door de Franschen ingevoerd, mogelijk door een uitlating van Thevet over oorsprong der Caraïbe(s) = magiërs der Tupi's van Brazilië uit de Canibale(s) ${ }^{1}$ ).

Op die eerste reis heeft men misschien op de kust van Haïti enkele Karaïben ontmoet. Doch op de tweede reis kwam men op een van hun vaste nederzettingen, op Guadeloupe. De scheepsarts Chanca vertelt daarvan het volgende: „Wij vroegen de vrouwen die gevangenen waren op dit eiland, wat voor volk hier was; zij antwoordden dat het Kariben waren.... Deze lieden doen strooptochten naar de andere eilanden en ontvoeren de vrouwen die ze kunnen vatten, vooral die jong en knap zijn. $Z_{i j}$ houden ze om hen te bedienen en als bijzitten, en zoo vele hebben zij er, dat we in 50 hutten geen Kariben zagen, en van de gevangenen waren er meer dan twintig, meisjes. Deze vrouwen zeggen ook, dat de Kariben van een ongeloofelijke wreedheid zijn; dat ze de zonen die ze bij hen hebben, opeten, en alleen die welke ze bij hun eigen vrouwen hebben, opvoeden. Van de mannen die ze kunnen vermeesteren, nemen ze die welke levend zijn, mee naar hun huizen om ze te slachten en die welke dood zijn, eten ze terstond op" ${ }^{2}$ ).

Met Karaïben van het vasteland (wij zullen aanstonds zien welk verschil er tusschen de twee volken is) kwam Amerigo Vespucci in 1499 of 1500 in aanraking op Trinidad. Hij vertelt: „Toen wij er aankwamen, zagen wij vele menschen aan den oever die naar ons keken als naar een wonder.... ze waren bang voor ons en gingen het bosch in, en met groote moeite stelden wij ze door teekens gerust en kwamen met hen in aanraking; en bevonden dat ze van een geslacht waren, dat men Kanibalen noemt en de meesten van dit volk leven van menschenvleesch.... ze eten elkaar niet op, maar gaan in hun vaartuigen die men kano's noemt en gaan eilanden of land van een hun vijandig volk nemen, of van anderen die niet hun vijanden zijn; van de vrouwen eten ze geen enkele; zij houden ze alleen als slavinnen" ${ }^{3}$ ).

De eilanden waar de Eiland-Karaïben woonden, van Grenada tot en met Santa Cruz (Barbados was niet bewoond), zijn niet

1) A. Thevet, La Cosmographie universelle, Paris 1575 p. 915 en 954-7; zie ook C. de Rochefort, Histoire des iles antilles, Rotterdam 1658 p. 324 vlg.

2) Hakluyt Soc. series II vol. LXV.

3) Brief, Sevilla 28 of 18 Juli 1500, afgedrukt o.m. A. Magnaghi, Amerigo Vespucci, Roma 1926, H. Vignaud, Americ Vespuce, Paris 1917. 
blijvend door de Spanjaarden bezet geweest; wel kwam men op Guadeloupe water laden en dreef er ruilhandel met de inboorlingen $\left.{ }^{1}\right)$. In de 17 e eeuw vestigden er zich Franschen, Engelschen, Nederlanders. Fransche paters Dominicanen verrichtten missiearbeid onder de Karaïben en hebben goede beschrijvingen van het volk en van hun taal nagelaten.

Een hunner, R. Breton, vertelt o.m.:

„Eindelijk heb ik van de Kapiteins van het eiland Dominica vernomen, dat de woorden Galibi [op het vasteland] en Caraibe [op de eilanden] namen waren die de Europeanen hun hadden gegeven en dat hun echte naam was kalinago, dat zij zich slechts van elkaar onderscheiden door de woorden ubaóbonum, baluebonum, d.w.z. van de Eilanden of van het vasteland, dat de eilanders Galibi's van het vaste land waren, die zich hadden afgezonderd van het vasteland om de Eilanden te veroveren, dat de Kapitein die hen geleid had, klein van lichaam was, maar groot in moed, dat hij weinig at en nog minder dronk, dat hij al de inboorlingen van het land had afgemaakt, behalve de vrouwen, die nog steeds iets van hun taal bewaard hebben, dat om de herinnering aan deze veroveringen te bewaren, hij de koppen der vijanden (dewelke de Franschen gevonden hebben) in holen in de rotsen aan de kust had laten brengen, opdat de vaders ze zouden toonen aan hun kinderen en zoo vervolgens aan al de anderen die van hen afstamden” "2). En: „.... hun stamvader Kalinago die met zijn gezin van het vasteland was gekomen, vestigde zich op Dominica. Hij had daar een lange lijn van afstammelingen en zag er nog de kleinkinderen van zijn kleinkinderen, die uit groote wreedheid, hem door vergift deden sterven. Maar hij werd veranderd in een visch van monsterlijke grootte, die zij Akaiuman $^{3}$ ) noemen en die nog springlevend in hun rivier is" " ${ }^{4}$ ).

Een andere missionaris, J. B. du Tertre, vertelt: „Men kan nog twee of drie dingen toevoegen, die duidelijk toonen, dat deze volken afstammen van de Galibi's: het eerste is, de gemeenschappelijke overlevering van alle Wilden die dit gelooven, en die verzekeren, dat de Galibi's, hun voorvaderen, in vroeger eeuwen zijn gekomen om de Iñerís die de inboorlingen van het land waren,

1) J. Rennard, Les Caraïbes, La Guadeloupe, Paris 1929 p. 76.

2) R. Breton, Dictionnaire Caraibe-Français, Auxerre 1665. Ed. facsimile, Leipzig 1892 p. 229-230.

s) Misschien $a k a=$ ziel $y u m a n=$ vader of vader-geest; ook akayuman $=$ kaaiman.

4) Breton bij Rennard, op. cit. p. 46. 
te bestrijden. Het tweede ding, dat dit bevestigt.... is het verschil in taal tusschen de mannen en de vrouwen, dat nog tegenwoordig bestaat; want zij zeggen dat dit verschil ontstaan is in den tijd van deze verovering, doordien de Galibi's alle mannen van deze Eilanden gedood hadden en slechts de vrouwen en meisjes gespaard hadden, aan wie ze jongelieden van hun natie tot echtgenoot gaven en de eene zoowel als de andere hun oorspronkelijke taal behielden. Als ge daar nu bijvoegt de overeenstemming in godsdienst, zeden en taal, dan is er geen aanleiding meer om te betwijfelen, dat ze afstammen van de Galibi's van het vasteland" 1).

Elders vinden wij vermeld, dat het overwonnen volk was ,een natie van Aruaken die de eilanden bewoonde" ${ }^{2}$ ).

Over de taal vertelt Labat: „De Caraïbes hebben drie soorten van spraken. De eerste, de gemeenste, en die, welke alle menschen spreken, is aan de mans, gelijk als eigen. De tweede is aan de vrouwen zodanig eigen, dat, hoewel de mans dezelve verstaan, zij zig voor onteert zouden houden, indien zij aan hunne wijven, indien dezelve de stoutheid hadden gehad van hen in deze taal aan te spreken, in die zelve taal geantwoord hadden. $Z$ ij verstaan de spraak van hare mans, en moeten zig daarvan bedienen, als zij dezelve aanspreeken; maar zij gebruiken ze nooit wanneer ze onder haar praten, en besteden daartoe geene andere, dan haar eige taal, welke van die der mans ten eenemaal verscheiden is. Daar is een derde taal, die alleenlijk bij de mans, die in den oorlog zijn geweest, en voornamentlijk bij de Oude bekent is; dog dit is veel meer een brabbeltaal, die zij uitgevonden hebben, dan een spraak. Zij gebruiken ze op Vergaderingen van aangelegentheit, welkers resolutien zij geheim willen houden; want de vrouwen en jonge luiden verstaan'er niets van" ${ }^{3}$ ).

Dat alles tezamen sluit eigenlijk reeds als een bus in elkaar. Kalina-go is inderdaad de naam (-go is eerbieds-suffix) waarmede de vastelands-Karaïben zichzelve noemen; I ner $i$ is de naam waarmede vele stammen van het vasteland, die verwant zijn aan de Aruwaken of Arawakken (arawak-maipure taalfamilie) zichzelve noemen.

Een paar eeuwen later heeft dan een Franschman die uit lief-

1) J. B. du Tertre, Histoire generale des Antisles. Paris 1671, II p. 361-2.

$\left.{ }^{2}\right)$ C. de Rochefort, op. cit. p. 329.

3) P. Labat, Nieuwe reizen naar de Franse Eilanden van America, Amsterdam 1725 (vertaling), III p. 202-3. 
hebberij indiaansche talen onderzocht, Lucien Adam, het EilandKaraïbisch vergeleken met het Kaliña of Galibi en met het Arawaksch. Hij slaagde erin, van 172 woorden en aanhangsels overeenkomst met het Kaliña aan te toonen; 113 daarvan behoorden tot de taal der mannen, 9 tot de taal der vrouwen, 45 tot de gemeenschappelijke taal, 5 onzeker. En bij 100 woorden en aanhangsels stelde hij overeenkomst met het Arawaksch vast; 5 daarvan behoorden tot de taal der mannen, 62 tot de taal der vrouwen, 30 tot de gemeenschappelijke taal, 3 onzeker ${ }^{1}$ ). Dat bevestigde dus volkomen de overlevering der Indianen.

Maar het was slechts een klein deel van den totalen woordenschat, waarbij Adam die overeenkomsten had kunnen vaststellen en van de historische argumenten waren hem slechts enkele bekend. En zoo kon het geschieden, dat later verschillende geleerden de zaak ondanks dat alles, in twijfel getrokken hebben.

$\mathrm{Nu}$ is het Eiland-Karaïbisch niet alleen van belang omdat geschiedenis en taalwetenschap wel willen weten, hoe het zit met die tweetaligheid, doch ook omdat het materiaal levert voor de vergelijkende studie der taalgroepen die tot zijn opbouw hebben medegewerkt. Daardoor kwam ik er, bij het bewerken van talen der karibische groep, mede in aanraking. Toen ik later ook de arawak-maipure-talen bestudeerd had en inmiddels veel nieuw materiaal beschikbaar was gekomen voor de vergelijking, was de tijd rijp voor een nieuw onderzoek van het Eiland-Karaïbisch. Ik heb dan de drie in het Honduras-Karaïbisch gedrukte Evangeliën geanalyseerd en vervolgens de woordenboeken van Breton, een 1000 blz., geheel uitgeplozen en ook de overige gegevens vergeleken en bovendien het Taino onderzocht. De uitkomsten heb ik in een voordracht op het internationaal linguisten-kongres te Rome in 1933 medegedeeld ${ }^{2}$ ).

Een voorbeeld. Het woordenboek van Breton vermeldt: soleil, huéy(o)u, f. cáchi, d.w.z. het eerstvermelde woord behoort tot de mannentaal, het tweede tot de vrouwentaal. Wij vergelijken en zien gemakkelijk, dat het woord der mannentaal overeenkomt met het karibische *weyu, zon, het woord der vrouwentaal met het arawak-maipure *kaši, in vele talen maan, in andere zon. Als men alle woorden onderzoekt, dan blijkt, dat de karibische ele-

1) L. Adam, Du parler des hommes et du parler des femmes dans la langue caraïbe, Paris 1879 (Extrait des Mémoires de l'Académie de Stanislas, pour 1878).

$\left.{ }^{2}\right)$ Verkort afgedrukt in Atti del III Congresso Internazionale dei Linguisti, Firenze 1935 p. 404-7. 
menten van het Eiland-Karaïbisch, zuiver Kaliña zijn, van het hedendaagsche Kaliña slechts verschillend door eenige oudere vormen. De arawak-maipure elementen zijn nogal nauw verwant aan het Arawaksch van Guyana, maar niet identiek, afkomstig dus uit een zelfstandige taal, die wij wel (zie hiervoor, aanhaling $\mathrm{du}$ Tertre) Iñeri mogen noemen.

In getallen samengevat, zijn de uitkomsten aldus:

Het Eiland-Karaïbisch heeft (afgerond in tientallen) 1650 wortels, behoorende tot de gemeenschappelijke taal, 490 behoorende tot de mannentaal, 370 behoorende tot de vrouwentaal.

Van 1510 woorden en aanhangsels kon de oorsprong worden vastgesteld, daaronder vrijwel alles wat grammatica is, wat dus het meest onmiddellijk menschelijke deel der taal betreft. Dat er toch nog zoo'n groote rest blijft, behoeft niet te verwonderen. Want de woordenboeken, die we vergelijken, zijn opgesteld nadat de talen elk een eigen ontwikkeling hadden doorgemaakt; bij het Iñeri ligt daar minstens 1000 jaar tusschen. Het laagste positieve percentage $(38 \%)$ leverden de namen van dieren en planten op. De woordenboeken zijn hier veelal onvolledig of de objekten moeilijk te identificeeren, en de fauna en flora der eilanden is ook niet geheel gelijk aan die van elders.

Van de woorden en aanhangsels, die geïdentificeerd werden, is: oorsprong Kaliña: mannen 370, vrouwen 20, gemeenschappelijk 420;

oorsprong Iñeri: mannen 30 , vrouwen 250 , gemeenschappelijk 430.

Men bedenke, wat dat zeggen wil, dat driehonderdzeventig verschillende woorden van de mannentaal der Eiland-Karaïben overeenkomen, en veelal nauwkeurig overeenkomen, met een woord der Kaliña's; enz.! Het is nu wel zeer duidelijk, dat Kaliñaelementen en Iñeri-elementen zich tot een nieuwe taal hebben samengesmolten, met gedeeltelijk behoud van een afscheiding. En dat past zeer goed bij de historische gegevens en bij de overlevering der Indianen.

De groote vraag, of zoo iets werkelijk mogelijk is, is hiermede voorgoed in bevestigenden zin beantwoord: het ís voorgekomen.

De veroveraars hadden waarschijnlijk wel vrouwen van het eigen volk bij zich; niettemin toont de latere taal, het EilandKaraïbisch, ten duidelijkste, dat de Iñeri-vrouwen, of ook de later geroofde Taino- en Arawaksche vrouwen, een belangrijke rol hebben gespeeld bij de vorming van het nieuwe volk, zoodat het verhaal van Chanca, dat de mannen de zoons, die ze bij een 
der onderworpen vrouwen hadden, doodden en opaten, wel overdreven of geheel onjuist geweest zal zijn.

De volgende generaties zijn zich altijd blijven beschouwen als het volk der Kalina-go (mannentaal) of Kaliponam (vrouwentaal), zoodat het matriarchaat, dat bij de veroveraars en zeer waarschijnlijk ook bij de onderworpenen heerschte, hier niet gegolden heeft.

De tweetaligheid, waarbij echter de vrouw den man slechts in diens taal mocht aanspreken, ontstond op natuurlijke wijze en is later vermoedelijk als strenge zede gehandhaafd, omdat men geen kans zag het Iñeri af te schaffen, maar het Kaliña in elk geval wilde handhaven. En het gebruik kon gereedelijk ingang vinden, omdat de Indianen een sterk gevoel ervoor hebben, dat de man en de vrouw verschillende wezens zijn en zich dienovereenkomstig hebben te gedragen. Dat blijkt bij de streng doorgevoerde arbeidsdeeling en in de magisch-religieuse gebruiken. Ook is het bij Kaliña's, Arawakken en andere volken van ZuidAmerika, gebruik dat bij uitroepen en dgl., de vrouwen een ander woord of een anderen vorm bezigen, dan de mannen.

Vóór, omstreeks 1400 n. Chr., de invasie der Kaliña's kwam, waren Iñeri's en Taino's bekend met de aanwezigheid van karibische volken op het vasteland. Dat blijkt uit de namen Kaliponam (vrouwentaal Eil. Kar.) en Caribe of dgl. (Taino), die men niet kan gehoord hebben van de veroveraars, omdat deze hun naam reeds hadden verkort tot Kaliña. Het is ook niet uitgesloten, dat aan den gewelddadigen overval, die Breton heeft geschilderd, kleine invasies of vreedzame kolonisatie op de Antillen is voorafgegaan. ${ }^{1}$ )

In het Eiland-Karaïbisch vindt men ook woorden uit het Tupi (Brazilië), die echter door de Kaliña's zijn medegebracht. De vroeger wel geuite meening, dat de Karaïben uit Florida zouden zijn gekomen, is geheel onjuist.

Het Taino, een der talen van de Groote Antillen, waarvan bij de oude spaansche schrijvers een 200-tal woorden bewaard zijn gebleven, was een taal der arawak-maipure-groep. De woordvergelijkingen, die Brinton destijds aanvoerde ${ }^{2}$ ), zijn voor een belangrijk deel onjuist, kunnen ook aangevuld worden; doch zijn gevolgtrekking was goed.

1) Zie over oud verkeer Sven Lovén, Über die Wurzeln der Tainischen Kultur, Göteborg 1924, p. 37.

2) D. G. Brinton, The Arawack Language of Guiana in its linguistic and ethnological relations. Transactions American Philosophical Society, Philadelphia 1871. 
Voor zoover uit het geringe materiaal te zien valt, was het Taino niet identiek aan het Iñeri.

Hoewel het mogelijk is, dat onder de niet-geïdentificeerde woorden van het Eiland-Karaïbisch, zich woorden bevinden, die overgenomen zijn van een oudere bevolking der Antillen, is het toch wel zeker, dat het Iñeri in hoofdzaak een arawak-maipure-taal was.

Volken van de arawak-maipure-familie woonden dus in 1492 van de Bahama's tot in Bolivia. De plek, van waar die stammen zijn uitgezwermd, moet m.i. eerder ergens in het Noordoosten van Zuid-Amerika gezocht worden, dan op de eilanden.

Op de Curaçao-groep zijn geen Karaïben geweest. Het heet, dat daar Indianen van den stam der Caquetias gewoond hebben, die ook de landstreek van Coro op den vasten wal bevolkte ${ }^{1}$ ), en waarvan, naar ik meen, vermoed wordt, dat zij een arawak-maipure-volk waren.

Hoe het de Eiland-Karaïben verder gegaan is? $\mathrm{Zij}$ hebben strijd gevoerd tegen de Spanjaarden, Franschen en Engelschen. De Nederlanders, die zich op St. Eustatius, Saba en St. Martin vestigden, hebben er, voor zoover mij bekend, geen Karaïben meer gezien; op Tobago daarentegen, hebben ze veel van hen te lijden gehad ${ }^{2}$ ). De strooptochten der Karaïben tegen de Taino's der Groote Antillen en Arawakken van het vasteland zijn opgehouden naarmate de Europeanen meer gezag kregen in die streken. Na een opstand zijn in 1796 een groot aantal Karaïben van Sint Vincent door het Engelsche Bestuur overgebracht naar Britsch Honduras. Van de Eiland-Karaïben zijn thans alleen op Dominica en Sint Vincent nog geringe resten aanwezig, doch de naar Honduras overgebrachten hebben zich daar sterk vermenigvuldigd ${ }^{3}$ ). En in hun taal is hun geschiedenis afgedrukt.

Daar vindt men dan een breede grondslag van Iñeri met vrij veel Kaliña-woorden en ook enkele resten van grammaticale vormen uit het Kaliña, die, als men de geschiedenis niet wist, voor onverklaarbare onregelmatigheden gehouden zouden worden. Dan wat spaansche woorden uit den ouden tijd, een paar engel-

1) P. A. Euwens, Coro; Amigoe di Curaçao 19 Nov. 1927.

2) Zie C. K. Kesler, Tobago, Een vergeten Nederlandsche Kolonie. De West-Ind. Gids X.

s) Zie $\mathrm{T}($ en) $\mathrm{K}($ ate), Ethnographische aanteekeningen omtrent de zwarte Caraïben (bespreking artikel E. Conzemius), De West-Ind. Gids X. Wat ik hier vermeld, geldt voor deze eeuw, doch misschien niet meer geheel voor 1935 . 
sche en nederlandsche woorden en heel veel fransche woorden die getuigenis afleggen van het vroegere werk der fransche missionarissen. En ten slotte, uit den tijd na de immigratie, engelsche en spaansche woorden en woorden uit indiaansche talen van Centraal-Amerika. Het verschil tusschen mannen- en vrouwentaal is nog steeds niet geheel verdwenen. 